\title{
Hysterectomy Patient
}

National Cancer Institute

\section{Source}

National Cancer Institute. Hysterectomy Patient. NCI Thesaurus. Code C158377.

A patient who is undergoing a hysterectomy. 